\title{
РТУТЬ В РЯСКЕ КАК ИНДИКАТОР ТЕХНОГЕНЕЗА НА ТЕРРИТОРИИ РОССИИ
}

\author{
Барановская Наталья Владимировна', \\ nata@tpu.ru
}

\author{
Барановская Анна Юрьевна', \\ kyzmen44@mail.ru
}

\author{
Капитонова Ольга Анатольевна², \\ kapoa.tkns@gmail.com \\ 1 Национальный исследовательский Томский политехнический университет, \\ Россия, 634050, г. Томск, пр. Ленина, 30. \\ 2 Тобольская комплексная научная станция Уральского отделения Российской академии наук, \\ Россия, 626152, г. Тобольск, ул. Академика Осипова, 15.
}

\begin{abstract}
Актуальность. Исследования обусловлены необходимостью поиска чувствительных индикаторов техногенеза, элементный состав которых может позволить получить объективную информацию об эколого-геохимической обстановке изучаемой территории. Ртуть отличается высокими токсикологическими свойствами по отношению к живому организму. Использование биообъектов, находящихся в начале пищевой цепочки, является наиболее информативным и объективным, а также может послужить важной информацией для дальнейшего прогнозирования экологической обстановки территории.

Цель: определить индикаторные способности элементного состава водных растений семейства рясковые (Lemnaceae) к эколого-геохимической обстановке различных урбанизированных территорий России на примере изучения концентраций ртути в ней.

Объекты: водное растение семейства рясковые (Leтnaceae), отличающееся повсеместной встречаемостью, высокой скоростью прироста биомассы и толерантностью к климатическим условиям окружающей среды.

Методика. Исследование проведено по единой методике в 65 населенных пунктах 46 регионов Российской Федерации. Oпределение валового содержания ртути в ряске проводилось методом атомно-абсорбционной спектрометрии.

Результаты. Рассмотрена роль одного из индикаторов техногенеза - водные растения семейства рясковые. Получены количественные оценки распределения ртути в макрофите на исследуемой территории, определено среднее содержание ртути в ряске по России (среднее медианное - 14,7 нг/2, среднее арифметическое - 18 нг/2). Обнаружены аномальные концентрации ртути в водном растении на территории Ставропольского края, Республик Северная Осетия-Алания и Башкоркостан, а также Кировской и Кемеровской областей. Эколого-геохимическая обстановка данных территорий может быть обусловлена влиянием техногенных фракторов, наиболее весомыми из которых является хлорно-щелочное производство. Отдельно изучена региональная специфика на примере Томского района Томской области, на территории которого подробно изучена зона влияния Северного промышленного узла.
\end{abstract}

\section{Ключевые слова:}

Pтуть, растения семейства рясковые (Lemnaceae), урбанизированная территория России,

Томский район Томской области, геохимический индикатор, природные и техногенные источники ртути.

\section{Введение}

Ртуть относится к высокотоксичным химическим элементам вследствие ее уникальных физико-механических и геохимических свойств, высокой мобильности, разнообразия форм миграции и специфики их трансформации в природных и техногенных средах. Значимым фактором степени роста ртутного загрязнения окружающей среды территорий служат преимущественно промышленные предприятия, которые используют данный экотоксикант в технологических циклах [1-3].

После трагедии, случившейся в префектуре Кумамото в г. Минамата (Япония) в 1956 г., концентрации и поведение ртути и ее соединений в окружающей среде стали иметь санитарно-гигиенический и экологический контроль федерального уровня, изменилась и степень очистки отходов производства, относящихся к 1-му классу опасности. Но, несмотря на данную положительную тенденцию в области экологической безопасности ряда стран, актуальность изучения механизмов ртутного загрязнения природных сред становится все выше. Особое внимание уделяется ком- понентам водной среды, являющимся менее устойчивыми к воздействию ртути [3-6].

Учитывая, что при прохождении по трофическим цепям концентрация металла возрастает в каждом следующем звене, определение экогеохимической обстановки с использованием биообъектов, находящихся в начале пищевой цепочки, является наиболее информативным и объективным, а также может послужить важной информацией для дальнейшего прогнозирования экологической обстановки территории. В настоящие время до конца считается нерешенной основная проблема биогеохимической индикации, а именно поиск биообъекта, отличающегося универсальностью и высокой степенью встречаемости в различных природно-климатических районах.

В настоящий момент большое внимание в области экологического мониторинга, фиторемедиации и биотестирования привлекают свободноплавующие водные растения семейства рясковые (Lemnaceae). По сравнению с другими макрофитами ряска отличается рядом преимуществ: простое морфологическое стро- 
ение, высокая скорость прироста биомассы, произрастание в различных климатических широтах, чувствительность к эколого-геохимической обстановке окружающей среды [7-9].

Стоит отметить, что L. Shun-Xing [10] в качестве потенциально дешевого адсорбента ртути предложил использовать именно ряску вследствие определения еe высокой адсорбционной способности к поглощению неорганической и органической ртути из водных растворов в лабораторных условиях.

Цель настоящей работы - определение индикаторных способностей водных растений семейства рясковые (Lemnaceae) к эколого-геохимической обстановке различных урбанизированных территорий России на примере изучения концентраций ртути в ней.

\section{Материалы и методы исследования}

Объектом исследования являлось водное растение семейства рясковые, отличающееся повсеместной встречаемостью, высокой скоростью прироста биомассы и толерантностью к климатическим условиям окружающей среды [4, 11-13].

Наиболее распространенными видами семейства Lemnaceae на территории Российской Федерации являются: Lemna turionifera Landolt, Spirodela polyrhiza (L.) Schleid., Lemna minor L. и Lemna trisulca L. $[14,15]$. Чаще всего указанные виды произрастают совместно, образуя общие фитоценозы, с большим или меньшим участием каждого вида в каждом конкретном сообществе растительного континуума. В этой связи в работе использована смесь представителей рясковых без разделения их по видам [14].

Полевые исследования проводились во время вегетационного периода макрофитов, с июня по август (с 2013 по 2017 гг.). Отобраны пробы растений семейства рясковых, произраставших на территории 65 населенных пунктов Российской Федерации (рис. 1).

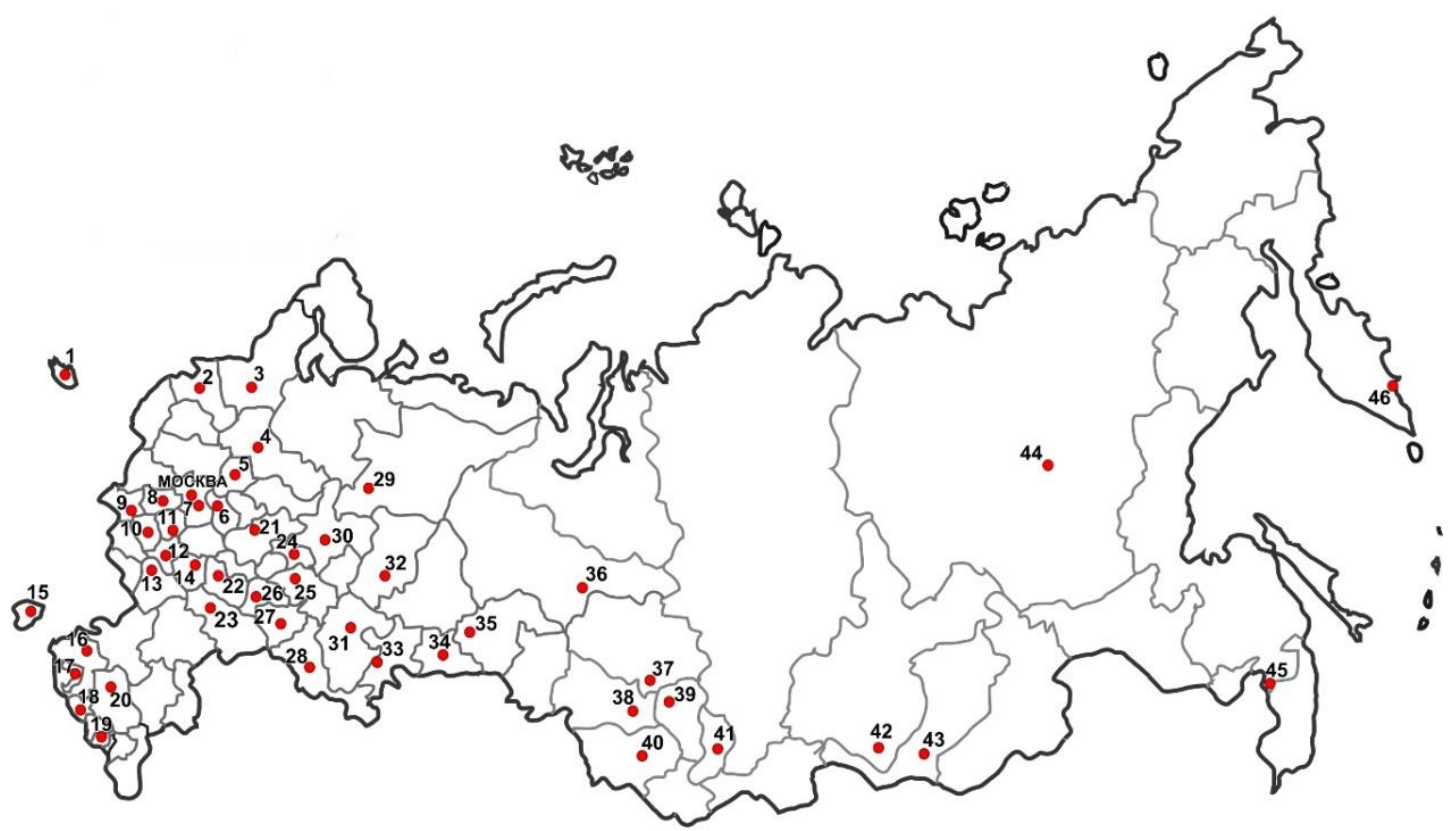

Рис. 1. Точки отбора проб ряски на территории Российской Федерачии: 1 - 2. Калининград, 2 - 2. Санкт-Петербург, 3 - д. Вехручей (Респ. Карелия), 4 - г. Вологда, 5 - г. Ярославль, 6 - д. Петушки (Владимировская обл.), 7 Московская обл. (г. Москва, г. Коломна), 8 - г. Мосальск, 9 - г. Брянск, 10 - г. Орел, 11 - д. Якиино (Тульская обл.), 12 - г. Липеик, 13 - п. Подгоренский (Воронежская обл.), 14 - г. Тамбов, 15 - г. Симферополь, 16 2. Краснодар, 17 - ст. Новосвободная (Респ. Адыгея), 18 - n. Новая Теберда (Респ. Карачаево-Черкесия), 19 c. Нижняя Саниба (Респ. Северная Осетия-Алания), 20 - г. Ставрополь, 21 - д. Боталово (Нижегородская обл.), 22 - n. Лесной (Пензенская обл.), 23 - г. Саратов, 24 - n. Знаменский (Респ. Марий Эл), 25 - n. Юган (Респ. Татарстан), 26 - г. Ульяновск, 27 - г. Самара, 28 - г. Оренбург, 29 - г. Сыктывкар, 30 - д. Проснииа (Кировская обл.), 31 - г. Уфа, 32 - с. Березовка (Пермский край), 33 - г. Магнитогорск, 34 - г. Курган, 35 2. Тюмень, 36 - г. Нижневартовск, 37 - Томский район (Томская обл.), 38 - г. Новосибирск (Академгородок), 39 - г. Кемерово, 40 - г. Барнаул, 41 - с. Туим (Респ. Хакасия), 42 - г. Иркутск, 43 - г. Улан-Удэ, 44 2. Якутск, 45 - г. Хабаровск, 46 - г. Петропавловск-Камчатский

Fig. 1. Duckweed sampling points in the Russian Federation: 1 - Kaliningrad, 2 - St. Petersburg, 3 - Vekhruchey (Karelia Republic), 4 - Vologda, 5 - Yaroslavl, 6-Petushki (Vladimir region), 7 - Moscow region (Moscow, Kolomna), 8 - Mosalsk, 9 - Bryansk, 10 - Orel, 11 - Yakshino (Tula region), 12 -Lipetsk, 13 - Podgorensky (Voronezh region), 14 Tambov, 15 - Simferopol, 16 - Krasnodar, 17 - Novosvobodnaya station (Adygea Republic), 18 - Novaya Teberda (Karachaevo-Cherkessia Republic), 19 - Nizhnyaya Saniba (North Ossetia-Alania Republic), 20 - Stavropol, 21 - Botalovo (Nizhny Novgorod region), 22 - Lesnoy (Penza region), 23 - Saratov, 24 - Znamensky (Mari El Republic), 25 - Yugan (Tatarstan Republic), 26 - Ulyanovsk, 27 - Samara, 28 - Orenburg, 29-Syktyvkar, 30 - Prosnitsa (Kirov region), 31 Ufa, 32 - Berezovka (Perm region), 33 - Magnitogorsk, 34 - Kurgan, 35 - Tyumen, 36 - Nizhnevartovsk, 37 - Tomsk district (Tomsk region), 38 -Novosibirsk (Akademgorodok), 39 - Kemerovo, 40 - Barnaul, 41 - Tuim (Khakassia Republic), 42 -Irkutsk, 43 - Ulan-Ude, 44 - Yakutsk, 45 - Khabarovsk, 46 - Petropavlovsk-Kamchatsky 
Пробы представителей семейства рясковых отбирали из природных бессточных водоемов, по трофическому состоянию относящихся к эвтрофным, с площадями зеркал преимущественно до $500 \mathrm{~m}^{2}$.

Аналитическая пробоподготовка заключалась в проведении родовой идентификации растений, удалении минеральных включений, а также иных видимых невооруженным глазом организмов. Далее пробы растений высушивались при комнатной температуре до воздушно-сухого состояния и гомогенизировались (истирались в агатовой ступке). Видовая идентификация исследуемых растений проведена О.А. Капитоновой на базе Тобольской комплексной научной станции Уральского отделения Российской академии наук.
Определение валового содержания ртути в ряске проводилось методом атомно-абсорбционной спектрометрии в Международном научно-образовательном центре «Урановая геология» Национального исследовательского Томского политехнического университета, в лаборатории микроэлементного анализа на ртутном анализаторе «РА-915+» (Россия) с приставкой «ПИРО-915+». Точность метода ААС подтверждалась использованием государственного стандартного образца состава листа березы ЛБ-1 (ГСО 8923-2007).

\section{Результаты исследования и обсуждение}

По результатам исследования определено валовое содержание ртути в ряске, произраставшей на территории 65 населенных пунктов России (рис. 2).

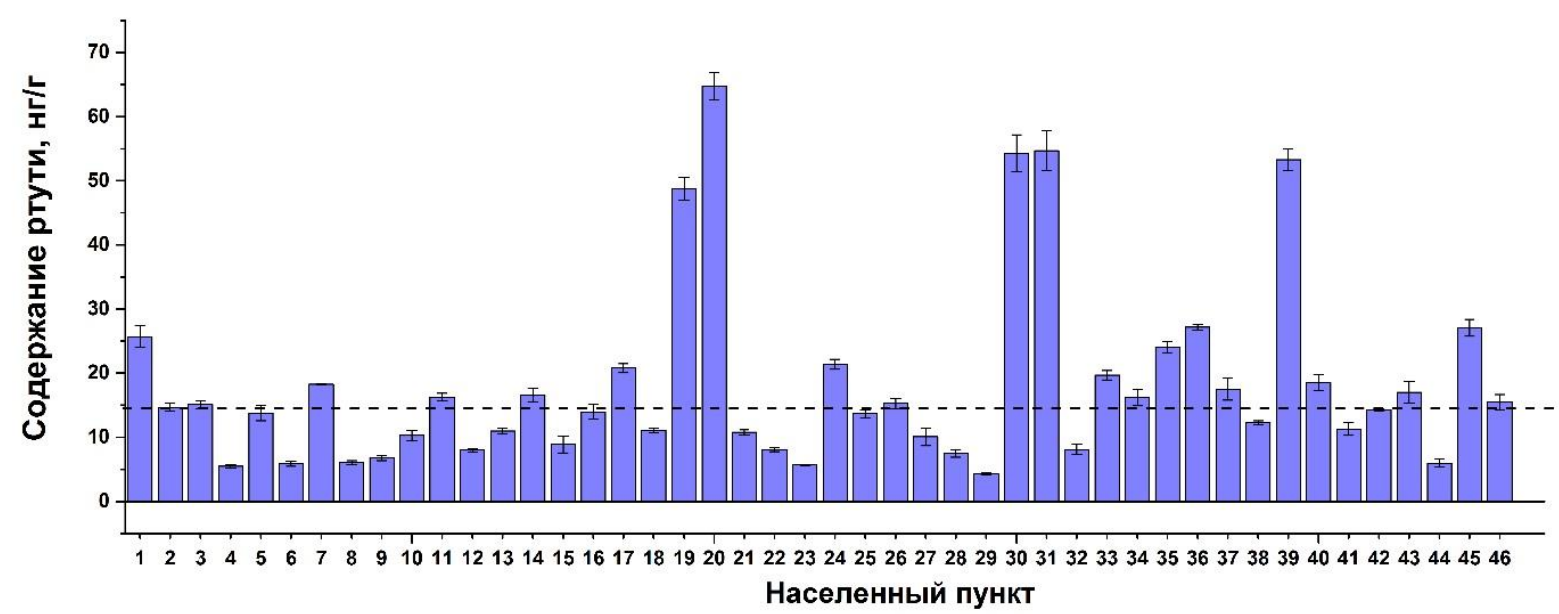

Рис. 2. Содержание ртути в сухом веществе ряски урбанизированных территорий России (пунктирная линия медианное значение содержания ртути в ряске на территории РФ): Условные обозначения представлены на puc. 1

Fig. 2. Mercury concentration in dry weight of duckweed from the urbanized territories of Russia (dashed line is the average mercury concentration of duckweed for Russian Federation): Symbols are shown in Fig. 1

Выполнена статистическая обработка полученных результатов анализа. Установлено, что распределение ртути в ряске на исследуемой территории статистически значимо отличается от нормального распределения, вследствие чего для оценки среднего взято медианное значение исследуемой выборки.

Среднее медианное значение ртути в ряске на территории Российской Федерации составляет 14,7 нг/г, что ниже медианного значения данного экотоксиканта для наземно-воздушных растений, листьев тополя, урбанизированных территорий Сибири и Дальнего Востока, которое составляет 23 нг/г [16]. Среднее арифметическое значение ртути для исследуемой выборки составляет 18 нг/г, что также не превышает фоновых значений ртути для макрофитов (20 нг/Г) [17].

По результатам исследования выявлено, что содержание ртути в ряске отличается неоднородностью распределения на исследуемой территории и варьирует в широких пределах: от 4,3 н/г (г. Сыктывкар) до 64,8 нг/г (г. Ставрополь), что может говорить о высо- кой степени чувствительности макрофитов к экогеохимической обстановке окружающей среды (рис. 2).

Более 70 \% выборки находится в пределах среднего $(14,7$ нг/г) и ниже. Наименьшие концентрации обнаружены в ряске, произраставшей на территориях д. Петушки (Владимирская обл.) $(5,9 \pm 0,4$ нг/г), г. Мосальска $(6,1 \pm 0,3 н г / \Gamma)$, г. Вологда $(5,5 \pm 0,3$ нг/г), г. Саратова $(5,7 \pm 0,1$ нг/г), г. Якутска $(6 \pm 0,6 н г / \Gamma)$ и г. Сык-

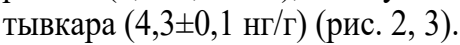

Стоит обратить внимание на пробы макрофитов, концентрации ртути в которых кратно превышают медианное значение по России. Такие повышенные содержания экотоксиканта характерны для следующих территорий: г. Ставрополь $(64,8 \pm 2,1$ нг/Г), д. Просница $(54,3 \pm 2,9$ нг/г), с. Нижняя Саниба $(48,8 \pm 1,8$ нг/г), г. Уфа $(54,7 \pm 3,1$ нг/г) и г. Кемерово $(53,3 \pm 1,7$ нг/г) (рис. 2, 3). Данные населенные пункты сконцентрированы преимущественно в западной части страны, в то время как восточная территория отличается содержанием ртути ниже среднего для ряски по России и низкой вариативностью (рис. 3). 


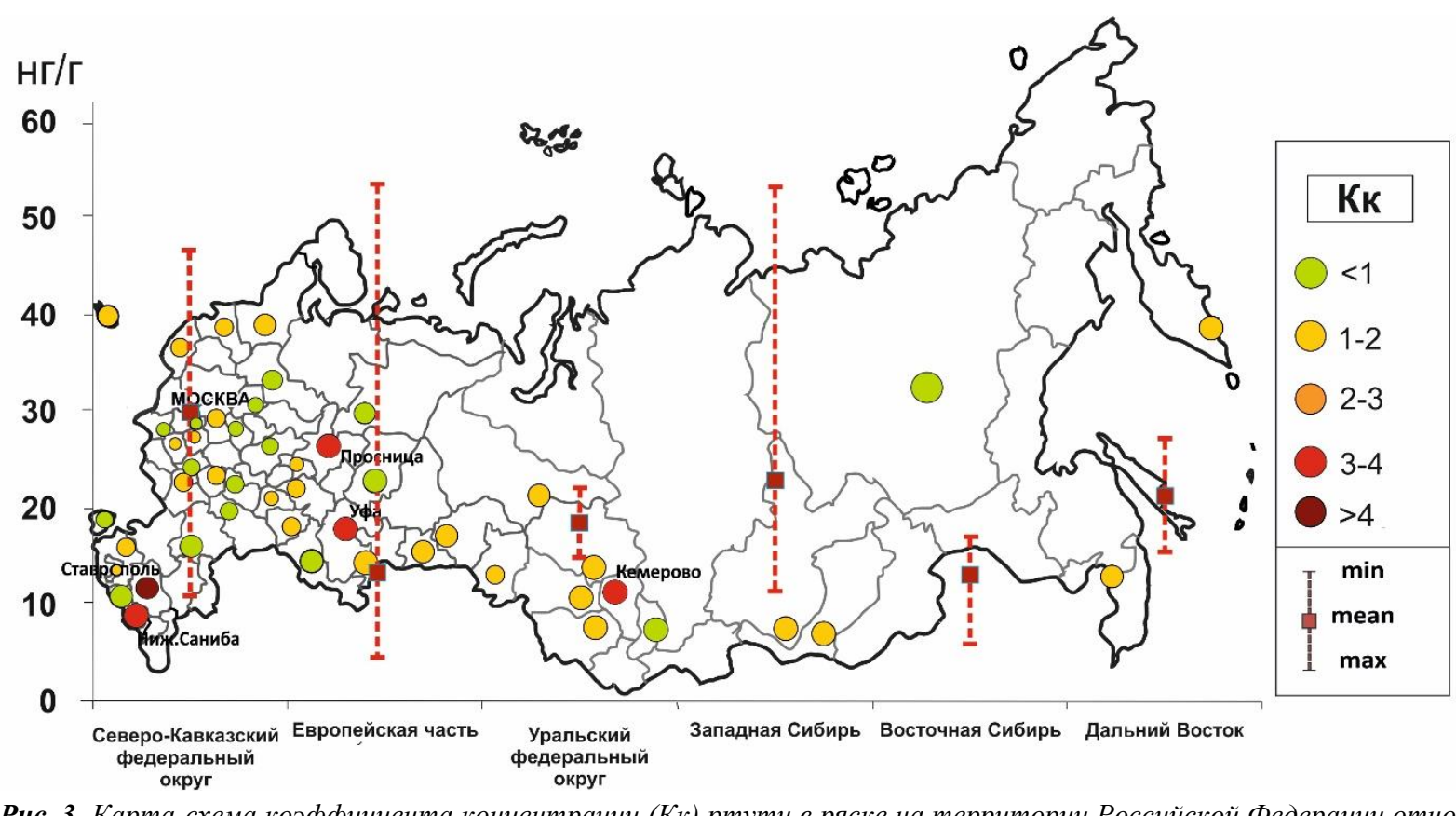

Рис. 3. Карта-схема коэффициента концентрации (Кк) ртути в ряске на территории Российской Федерации относительно среднего медианного значения элемента по выборке

Fig. 3. Schematic map of mercury concentration coefficient $(C c)$ in duckweed from the Russian Federation relative to the average median value of the element in the samples

Концентрирование ртути растениями семейства Lemnaceae характерно для субъектов Российской Федерации, в которых сосредоточены крупные производства, в технологических циклах которых используется данный экотоксикант и с выбросами поступает в окружающую среду (рис. 1) [1,2,18].

Ярким примером влияния техногенеза могут быть аномально высокие концентрации ртути в ряске $(54,3 \pm 2,9$ нг/г), произраставшей в заводи р. Просница, Кировской области. Эколого-геохимическая ситуация данного района сформировалась вследствие воздействия ОАО «Кирово-Чепецкого химкомбината», в технологии которого для производства хлора и каустической соды используется ртутный электрод [19]. Наши данные подтверждаются ранее проведенными на этой территории исследованиями других авторов по изучению содержания ртути в различных компонентах природной среды. Так, по данным С.Г. Скугоревой [19], Т.А. Мусихиной $[20,21]$, в районе р. Елховки и ее притоков (к которым относится р. Просница и ее акватория) Кировской области обнаружены концентрации ртути в различных природных компонентах, кратно превышающие фоновые значения для данного района. По некоторым данным, предприятие имеет проблему, связанную с высоким уровнем грунтовых вод в районе расположения корпуса электролиза, вследствие чего возможно загрязнение близкорасположенных к предприятию поверхностных вод [2].

Аномальные концентрации ртути в ряске на территории г. Кемерово $(53,3 \pm 3,2$ нг/г) могут говорить об эколого-геохимической ситуации района, сложившейся вследствие влияния природного и техногенного факторов. Ввиду наличия крупнейшего каменноугольного бассейна районы Кузбасса определяются различными отраслями промышленности (горнодо- бывающая, горнообрабатывающая, химическая, металлургическая и т. д.). Одним из крупных индустриальных центров Кемеровской области является г. Кемерово - центр химического производства.

Выявленные высокие концентрации ртути в макрофитах на данной территории могут быть следствием высокой развитости углехимической промышленности района.

По данным некоторых авторов, повышенные содержания ртути в почвах $(0,06-0,20$ мг/кг) зарегистрированы в районах активной угледобычи и в крупных промышленных центрах Кемеровской области. Стоит отметить, что наиболее высокие концентрации экотоксиканта обнаружены именно в верхнем горизонте, содержащем высокую концентрацию подвижных компонентов и тесно взаимодействующим с поверхностными водами (0,09-0,37 мг/кг) [22].

В отношении регионального характера распределения ртути в ряске наиболее подробно изучена территория Томского района Томской области, которая характеризуется крайне неравномерным распределением промышленных объектов, с сосредоточением основных крупных предприятий именно в Томском районе $[23,24]$.

Средние содержание ртути в ряске на территории Томского района соответствует среднероссийским показателям (18 нг/г) и не превышает фоновых значений для макрофитов. При этом наблюдаются локальные участки, где содержание ртути значительно превышает фон (20\% от всей выборки). К ним относятся такие населенные пункты, как: д. Георгиевка $(34,1 \pm 2,8$ нг/г), д. Надежда $(30,5 \pm 2,8$ нг/г), с. Наумовка $(27,9 \pm 1,8$ нг/г), п. Кузовлево $(29,9 \pm 1,1$ нг/г).

Данные населенные пункты включают преимущественно водоемы, расположенные в основной розе 
ветров в летний сезон (с юго-юго-запада на северосеверо-восток), непосредственно прилегающие к г. Томску и находящиеся в 30-километровой зоне влияния предприятий Северного промышленного узла города Томска (СПУ), в состав которого входит комплекс из более чем 33 разнопрофильных объектов, в том числе крупнейшие комплексы Сибирского химического комбината и ООО «Томскнефтехим» (ныне «СИБУР»). Эта территория характеризуется специфической эколого-геохимической ситуацией ртутного загрязнения, сформировавшейся вследствие длительного воздействия СПУ [23, 24].

Наши данные показали, что по содержанию ртути в растениях семейства рясковые территорию Томского района можно разделить на три характерные группы.

К первой группе (группа А) относятся населенные пункты, расположенные по преобладающей розе ветров и находящиеся в зоне воздействия предприятий
СПУ. Ряска, произраставшая в данных поселениях, характеризуется наиболее высоким содержанием ртути (до 34 нг/г). Также стоит отметить, что концентрация экотоксиканта возрастает по мере приближения к источнику воздействия.

Ко второй группе (группе В) относятся населенные пункты, расположенные в Томь-Обском междуречье и вдоль реки Томь. Среднее содержание ртути в исследуемом растении составляет 16 нг/г. Мы предполагаем, что причиной сложившейся экологогеохимической ситуации для населенных пунктов второй группы является трансграничный перенос поллютантов вдоль реки с территории Кузбасса (Кемеровская область).

Третья группа (группа С) представляет собой поселения Томского района, расположенные на значительном расстоянии от основных объектов техногенного воздействия (юг и юго-запад района), концентрации ртути здесь не превышают 10 нг/г (рис. 4).

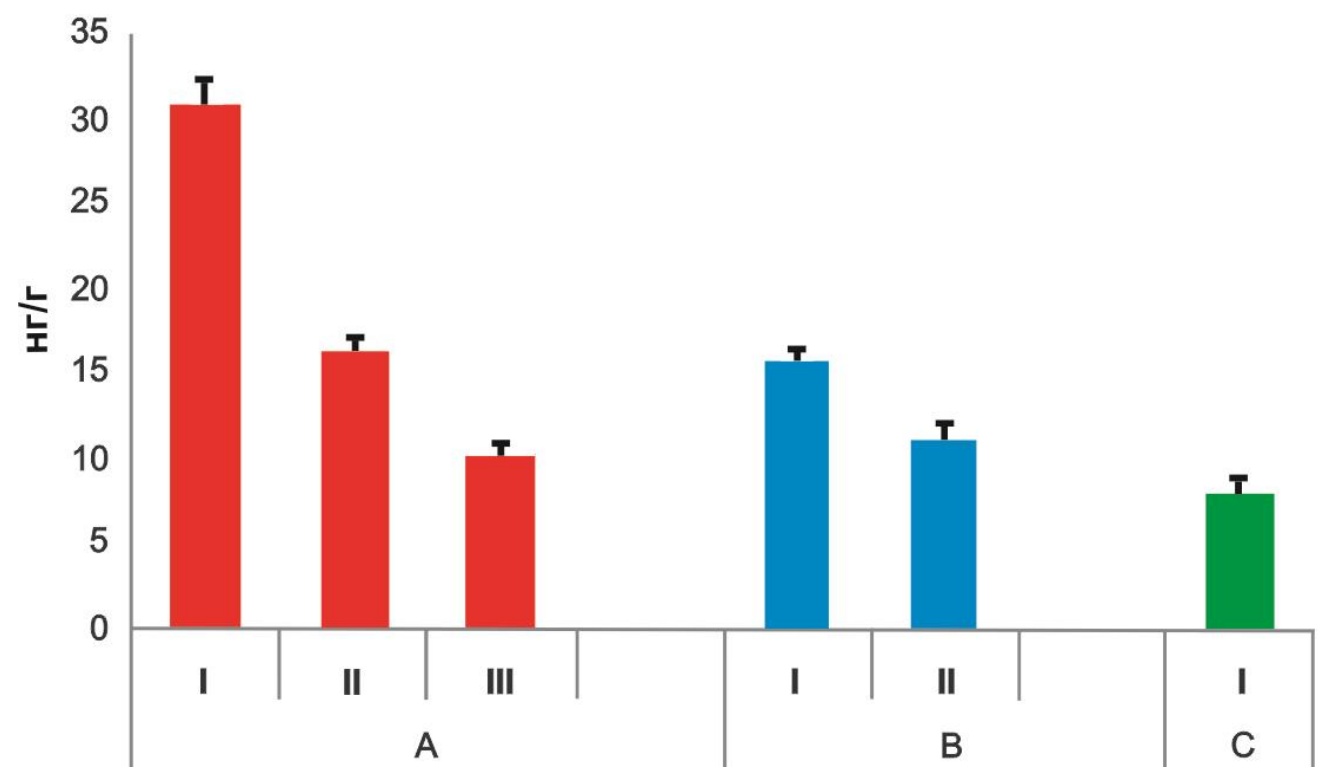

Pис. 4. Содержание ртути в ряске на территории Томского района (сухое вещество, нг/2). Населенные пункты сгруппированы по направлениям: А - северо-восток (I- д. Георгиевка, д. Надежда, с. Наумовка, п. Кузовлево, II - Малиновка, III - n. Светльй, n. Копьлово); B - северо-запад (I-c. Моряковский Затон, n. Самусь, II -

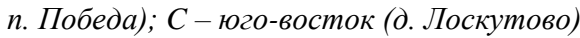

Fig. 4. Mercury concentration in duckweed from the Tomsk region. Settlements are grouped as: A - north-east (I Georgievka, Nadezhda, Naumovka, Kuzovlevo, II - Malinovka, III - Svetly, Kopylovo); B - north-west (I - Moryakovsky Zaton, Samus, II - Pobeda); C-south-east (Loskutovo)

Таким образом, полученные данные могли констатировать тот факт, что растения семейства рясковые являются чувствительным индикаторным объектом.

\section{Заключение}

В результате проведенных исследований получена информация о среднем содержании ртути в пресноводных растениях семейства рясковых (Lemnaceae) на территории России (среднее медианное - 14,7 нг/г, среднее арифметическое - 18 нг/г). Наименьшие значения ртути обнаружены в ряске, произраставшей на урбанизированных территориях Владимировской, Вологодской, Саратовской областей, Республик Якутия и Коми.
Концентрации ртути в ряске, произраставшей на территории Ставропольского края, Республик Северная Осетия-Алания и Башкоркостан, а также Кировской и Кемеровской областей, имеют аномальные значения и преимущественно определены влиянием техногенных факторов. Можно предположить, что обнаруженная эколого-геохимическая обстановка на территории Республики Башкоркостан и Кировской области имеет одинаковую природу, сложившуюся вследствие влияния хлорно-щелочного производства. По результатам степени концентрирования ртути в ряске можно выделить следующие потенциальные источники экотоксиканта: химические заводы по производству каустической соды и хлора ртутным методом, углехими- 
ческая промышленность, а также зоны, отличающиеся высокой частотой встречаемости крупных техногенных объектов на локальной территории.

Степень воздействия промышленных объектов на концентрирование ртути ряской ярко продемонстрированы на территории Томской области, Томского района. Участки с высоким содержанием поллютанта в ряске сконцентрированы в зоне, характеризующейся наибольшим техногенных прессингом, также наблюдается увеличение концентраций ртути по мере приближения к источнику загрязнения.

Таким образом, полученные результаты позволили выявить высокую чувствительность исследуемого биообъекта к ртути в окружающей среде, при этом аномальные концентрации экотоксиканта в ряске могут сигнализировать о воздействии именно антропогенного источника. Учитывая повсеместную встречаемость растений семейства рясковых и при дальнейшем проведении ряда исследований по определению механизмов накопления ртути в ней, данный объект возможно использовать как универсальный индикатор ртутного загрязнения окружающей среды.

\section{СПИСОК ЛИТЕРАТУРЫ}

1. Янин Е.П. Ртуть в России: производство и потребление. - М.: ИМГРЭ, 2004. - 38 c.

2. Pollman C.D., Rumbold D.G., Axelrad D.M. Mercury and the Everglades. A Synthesis and Model for Complex Ecosystem Restoration. - Cham: Springer, 2019. - 109 p.

3. Paulson A.J., Marvin-DiPasquale M.C., Moran P.W., Stewart A.R., DeWild J.F., Toft J., Agee J.L., Kakouros E., Kieu Le H., Carter B., Sheibley R.W., Cordell J., Krabbenhoft D.P. Mercury methylation and bioaccumulation in Sinclair Inlet, Kitsap County, Washington: U.S. - Reston: U.S. Geological Survey, 2018. - 63 p.

4. Wollenberg J.L., Peters S.C. Diminished mercury emission from waters with duckweed cover // Journal of Geophysical Research: Biogeosciences. - 2009. - V. 114. - № G2. - P. 1-10.

5. Wang R., Wang P., Wang C. Mercury distribution, speciation and potential ecological risk assessment in sediments from Lake Taihu, China // Toxicological \& Environmental Chemistry. - 2018. V. 100. - № 4. - P. 425-439.

6. Иванов А.Ю. Закономерности распределения химических элементов в вертикальном профиле донных отложений слабопроточных водоемов Томского района // Известия Томского политехнического университета. Инжиниринг георесурсов. 2016. - T. 327. - № 2. - C. 88-101.

7. Phytoremediation performance of Lemna communities in a constructed wetland system for wastewater treatment / S. Ceschin, V. Sgambato, N.T.W. Ellwood, V. Zuccarello // Environmental and experimental botany. - 2019. - V. 162. - P. 67-71.

8. Ziegler P., Sree K.S., Appenroth K.J. Duckweed biomarkers for identifying toxic water contaminants? // Environmental Science and Pollution Research. - 2019. - V. 26. - № 15. - P. 14797-14822.

9. Uranium biosorption by Lemna sp. and Pistia stratiotes / L.C. Vieira, L.G. Araujo, R.V.P. Ferreira, E.A. Silva, R.L.S. Canevesi, J.T. Marumoa // Journal of environmental radioactivity. - 2019. - V. 203. - P. 179-186.

10. Thorough removal of inorganic and organic mercury from aqueous solutions by adsorption on Lemna minor powder / L. Shun-Xing, Z. Feng-Ying, H. Yang, N.J. Jian-Cong // Hazardous Materials. 2011. - V. 186. - P. 423-429.

11. Varga M., Horvatic J., Celic A. Short term exposure of Lemna minor and Lemna gibba to mercury, cadmium and chromium // Central European Journal of Biology. - 2013. - V. 8. - № 11. P. 1083-1093.

12. Duckweed as human food. The influence of meal context and information on duckweed acceptability of Dutch consumers / M.F.A. de Beukelaar, G.G. Zeinstra, J.J. Mes, A.R.H. Fischer // Food quality and preference. - 2019. - V. 71. - P. 76-86.
Авторы благодарят $и$ выражают особую признательность за рекомендации и незаменимые советь доктору геол.-минерал. наук, профессору Леониду Петровичу Рихванову, Нине Александровне Осиповой и Елене Евгеньевне Ляпиной за помощь в освоении атомноабсорбционного анализа и всем, кто бескорыстно помог в сборе материала: Надежде Стрюк (г. Воронеж), Дамиру Робертовичу Каримову (2. Бор), Александру Валерьевичу Тарасову (2. Коломна), Кристине Федосовой (2. Москва), Анастасии Андреевне Зориной (2. Кирово-Чепеик), Дарье Сергеевне Денисовой (2. Орел), Федору Марущак (г. Москва), Екатерине Алексеевне Монаховой (2. Омск), Николаю Владимировичу Торговкину (2. Якутск), Анастасии Олеговне Сороке и Олегу Витальевичу Сороке (2. Таймет), Агате Андреевне Шилениной (2. Бийск), Никите Шангину (2. Санкт-Петербург), Екатерине Евгеньевне Михайловой (2. Екатеринбург), Павлу Сергеевичу Шатиафу (2. Партизанск), Анне Кондратьевой (2. Псков), Евгению Анатольевичу Миханьтьеву (г. Новосибирск), Заурбеку Владимировичу Дзучеву (2. Владикавгаз), Анастасии Георгиевне Воробьевой (2. Владимир), Ольге Валентиновне Мартьловой и ее ученикам (2. Мосальск) и многим другим.

13. Sasmaz M., Obek E., Sasmaz A. The accumulation of La, Ce and $\mathrm{Y}$ by Lemna minor and Lemna gibba in the Keban gallery water, Elazig Turkey // Water and Environment Journal. - 2018. V. 32. - № 1. - P. 75-83.

14. Böcük H., Yakar A., Türker O.C. Assessment of Lemna gibba L.(duckweed) as a potential ecological indicator for contaminated aquatic ecosystem by boron mine effluent // Ecological indicators. - 2013. - V. 29. - P. 538-548.

15. Капитонова О.А. Материалы к биологии и экологии рясковых (Lemnaceae) Сибири // Проблемы ботаники Южной Сибири и Монголии. - 2019. - V. 1. - № 18. - C. 127-131.

16. Ртуть в листьях тополя на урбанизированных территориях Юга Сибири и Дальнего Востока / Д.В. Юсупов, Л.П. Рихванов, Ю.В. Робертус, Е.Е. Ляпина, Е.М. Турсуналиева, Н.В. Барановская, Н.А. Осипова // Экология и промышленность России. - 2018. - Т. 22. - № 12. - С. 56-62.

17. Никаноров А.М., Жулидов А.В., Покаржевский А.Д. Биомониторинг тяжелых металлов в пресноводных экосистемах. Л.: Гидрометеоиздат, 1985. - 144 с.

18. Estimating chemical footprint: contamination with mercury and its compounds / N. Tarasova, A. Makarova, P. Fantke, P. Shlyakhov // Pure and Applied Chemistry. - 2018. - V. 90. - № 5. - P. 857-868.

19. Скугорева С.Г., Ашихмина Т.Я. Содержание ртути в компонентах природной среды на территории вблизи КировоЧепецкого химического комбината // Известия Коми научного центра УРО РАН. - 2012. - Т. 11. - № 3. - С. 39-45.

20. Влияние выпусков промышленных стоков на формирование химического состава водотоков в границах территории Кирово-Чепецкой природно-техногенной системы / Т.А. Мусихина, Ю.А. Гарюгин, Е.А. Земцова, С.А. Казиенков // Известия Самарского научного центра Российской академии наук. 2015. - Т. 17. - № 6. - С. 123-127.

21. Эбериль В.И., Трегер Ю.А. Выбросы ртути с предприятий, производящих хлор и каустик в России // Химическая промышленность сегодня. - 2005. - № 1. - С. 32-38.

22. Маликова И.Н., Аношин Г.Н., Бадмаева Ж.О. Подвижные формы ртути в почвах природных и природно-техногенных ландшафтов // Геология и геофизика. - 2011. - Т. 52. - № 3. - С. 409-425.

23. Адам А.М. Экология Северного промышленного узла г. Томска. Проблемы и решения. - Томск: Изд-во ТГУ, 1994. - 260 с.

24. Эколого-геохимические особенности природных сред Томского района и заболеваемость / Л.П. Рихванов, Е.Г. Язиков, Ю.И. Сухих, Н.В. Барановская, В.Т. Волков, Н.Н. Волкова, В.В. Архангельский, Т.А. Архангельская, О.А. Денисова, А.Ю. Шатилов, Е.П. Янкович. - Томск: Курсив, 2006. - 216 с.

Поступила 17.06.2020 2. 


\section{Информация об авторах}

Барановская Н.В., доктор биологических наук, профессор отделения геологии Инженерной школы природных ресурсов Национального исследовательского Томского политехнического университета.

Барановская A.Ю., аспирант отделения геологии Инженерной школы природных ресурсов Национального исследовательского Томского политехнического университета.

Капитонова O.A., кандидат биологических наук, доцент, ведущий научный сотрудник группы экологии живых организмов Отдела экологических исследований Тобольской комплексной научной станции Уральского отделения Российской академии наук. 
UDC 504.064:550.42

\title{
MERCURY IN DUCKWEED AS AN INDICATOR OF TECHNOGENESIS IN RUSSIA
}

\author{
Natalya V. Baranovskaya ${ }^{1}$, \\ kyzmen44@mail.ru
}

\section{Anna Yu. Baranovskaya1, nata@tpu.ru}

\author{
Olga A. Kapitonova², \\ kapoa.tkns@gmail.com \\ 1 National Research Tomsk Polytechnic University, \\ 30, Lenin avenue, Tomsk, 634050, Russia. \\ 2 Tobolsk Complex Scientific Station of Ural Branch of Russian Academy of Sciences, \\ 15, Academician Osipov street, Tobolsk, 626152, Russia.
}

Relevance. The studies are determined by the need to find the sensitive technogenesis indicators, which elemental composition can show the ecological and geochemical situation of the territory. Mercury have negative toxicological influence on living organism. Biological objects at the beginning of food chain could be informative and objective indicators of environmental situation and can have important information for further predictions.

The aim of the research is to determine the indicator abilities of Lemnaceae family aquatic plants to the ecological and geochemical situation of various urbanized territories in Russia by studying concentration of mercury.

Objects: an aquatic plant of the duckweed family (Lemnaceae), characterized by widespread occurrence, high biomass growth rate and tolerance to climatic environmental conditions.

Methodology. The study was carried out according to a single methodology in 65 settlements from 46 regions of the Russian Federation. The determination of gross mercury in duckweed was carried out by atomic absorption spectrometry.

Results. The role of aquatic plant of the duckweed family as a geo-indicator of technogenesis is considered. The distribution of mercury in macrophyte from the study area was discovered, the average mercury content in duckweed for Russia (average median - 14,7 ng/g, arithmetic average $-18 \mathrm{ng} / \mathrm{g}$ ) was calculated. The abnormally high concentrations of mercury were determined in an aquatic plant from the Stavlopol Krai, the Republic of North Ossetia-Alania and Bashkorkostan, Kirov and Kemerovo Regions. The ecological and geochemical situation in these territories may be influenced by technogenic factors, such as chlorine-hydroxide production. The regional specificity of the Tomsk region were studied individually. The influence of the Northern industrial zone was particularly studied there.

\section{Key words:}

Mercury, duckweed, urbanized territory of Russia, Tomsk region, geochemical indicator, natural and technogenic sources of mercury.

The authors thank and express special appreciation for the recommendations and irreplaceable advice to the Professor L.P. Rikhvanov, N.A. Osipova and E.E. Lyapina for help in performing atomic-absorption analysis and for all those who helped in collecting material disinterestedly: N. Struk (Voronezh), D.R. Karimov (Bor), A.V. Tarasov (Kolomna), K. Fedosova (Moscow), A.A. Zorina (Kirovo-Chepetsk), D.S. Denisova (Oryol), F. Marushchak (Moscow), E.A. Monakhova (Omsk), N.V. Torgovkin (Yakutsk), A.O. Soroka and O.V. Soroka (Taishet), A.A. Shilenina (Biysk), N. Shangin (St. Petersburg), E.E. Mikhailova (Yekaterinburg), P.S. Shatiaf (Partizansk), A. Kondratyeva (Pskov), E.A. Mekhantyev (Novosibirsk), Z.V. Dzutsev (Vladikavgaz), A.G. Vorobyeva (Vladimir), O.V. Martynova and her students (Mosalsk) and others.

\section{REFERENCES}

1. Yanin E.P. Rtut v Rossii: proizvodstvo i potreblenie [Mercury in Russia: production and consumption]. Moscow, IMGRE Publ., 2004. $-38 \mathrm{p}$.

2. Pollman C.D., Rumbold D.G., Axelrad D.M. Mercury and the Everglades. A Synthesis and Model for Complex Ecosystem Restoration. Cham, Springer, 2019. 109 p.

3. Paulson A.J., Marvin-DiPasquale M.C., Moran P.W., Stewart A.R DeWild J.F., Toft J., Agee J.L., Kakouros E., Kieu Le H. Carter B., Sheibley R.W., Cordell J., Krabbenhoft D.P. Mercury methylation and bioaccumulation in Sinclair Inlet, Kitsap County. Washington: U.S. Reston, U.S. Geological Survey, 2018. 63 p.

4. Wollenberg, J.L., Peters S.C. Diminished mercury emission from waters with duckweed cover. Journal of Geophysical Research: Biogeosciences, 2009, vol. 114, no. G2, pp. 1-10.

5. Wang R., Wang P., Wang C. Mercury distribution, speciation and potential ecological risk assessment in sediments from Lake Taihu, China. Toxicological \& Environmental Chemistry, 2018, vol. 100, no. 4, pp. 425-439.

6. Ivanov A.Yu. Patterns of the distribution of chemical elements in the vertical profile of bottom sediments of low-flow reservoirs of the Tomsk region. Bulletin of the Tomsk Polytechnic University. Geo Assets Engineering, 2016, vol. 327, no. 2. pp. 88-101. In Rus.

7. Ceschin S., Sgambato V., Ellwood N.T.W., Zuccarello V. Phytoremediation performance of Lemna communities in a constructed wetland system for wastewater treatment. Environmental and experimental botany, 2019, vol. 162, pp. 67-71.

8. Ziegler P., Sree K.S., Appenroth K.J. Duckweed biomarkers for identifying toxic water contaminants? Environmental Science and Pollution Research, 2019, vol. 26, no. 15, pp. 14797-14822.

9. Vieira L.C., Araujo L.G., Ferreira R.V.P., Silva E.A., Canevesi R.L.S., Marumoa J.T. Uranium biosorption by Lemna sp. and Pistia stratiotes. Journal of environmental radioactivity, 2019, vol. 203, pp. 179-186.

10. Shun-Xing L., Feng-Ying Z., Yang H., Jian-Cong N.J. Thorough removal of inorganic and organic mercury from aqueous solutions by adsorption on Lemna minor. Hazardous Materials, 2011, vol. 186 , pp. 423-429.

11. Varga M., Horvatic J., Celic A. Short term exposure of Lemna minor and Lemna gibba to mercury, cadmium and chromium. Central European Journal of Biology, 2013, vol. 8, no. 11, pp. 1083-1093. 
12. Beukelaar M.F.A., Zeinstra G.G., Mes J.J., Fischer A.R.H. Duckweed as human food. The influence of meal context and information on duckweed acceptability of Dutch consumers. Food quality and preference, 2019, vol. 71, pp. 76-86.

13. Sasmaz M., Obek E., Sasmaz A. The accumulation of La, Ce and $\mathrm{Y}$ by Lemna minor and Lemna gibba in the Keban gallery water, Elazig. Water and Environment Journal, 2018, vol. 32, no. 1, pp. $75-83$.

14. Böcük H., Yakar A., Türker O.C. Assessment of Lemna gibba L. (duckweed) as a potential ecological indicator for contaminated aquatic ecosystem by boron mine effluent. Ecological indicators, 2013, vol. 29, pp. 538-548.

15. Kapitonova O.A. Materialy k biologii i ekologii ryaskovykh (Lemnaceae) Sibiri Materials about biology and ecology of duckweed (Lemnaceae) of Siberia. Botanical problems of Southern Siberia and Mongolia, 2019, vol. 1, no. 18, pp. 127-131. In Rus.

16. Yusupov D.V., Rikhvanov L.P., Robertus Yu.V., Lyapina E.E., Tursunalieva E.M., Baranovskaya N.V., Osipova N.A.. Mercury in Poplar Leaves in the Urbanized Areas of Southern Siberia andthe Far East. Ecology and Industry of Russia, 2018, vol. 22, no. 12, pp. 56-62. In Rus.

17. Nikanorov A.M., Zhulidov A.V., Pokarzhevsky A.D. Biomonitoring tyazhelykh metallov $v$ presnovodnykh ekosistemakh [Biomonitoring of heavy metals in freshwater ecosystems], Leningrad, Gidrometeoizdat Publ., 1985. 144 p.

18. Tarasova N., Makarova A., Fantke P., Shlyakhov P. Estimating chemical footprint: contamination with mercury and its compounds. Pure and Applied Chemistry, 2018, vol. 90, no. 5, pp. 857-868.

19. Skugoreva S.G., Ashikhmina T.Ya. The mercury content in the components of the environment in the territory near the KirovChepetsk chemical plant. Bulletin of the Komi Scientific Center,
Ural Branch of the Russian Academy of Sciences, 2012, vol. 11, no. 3, pp. 39-45. In Rus.

20. Musikhina T.A., Garyugin Yu.A., Zemtsova E.A., Kazienkov S.A. The effect of industrial effluent releases on the formation of the chemical composition of watercourses within the boundaries of the Kirov-Chepetsk natural-technogenic system. Bulletin of the Samara Scientific Center of the Russian Academy of Sciences, 2015, vol. 17, no. 6, pp. 123-127. In Rus.

21. Eberil V.I., Treger Yu.A. Mercury emissions from enterprises producing chlorine and caustic in Russia [Mercury emissions from enterprises producing chlorine and caustic in Russia]. Khimicheskaya promyshlennost segodnya, 2005, no. 1, pp. 32-38

22. Osipova N.A., Bykov A.A., Talovskaya A.V., Nikolaenko A.N., Yazikov E.G., Larin S.A. The influence of coal mining enterprises on the pollution of the snow cover of the adjacent urban areas (for example, Mezhdurechensk). Bulletin of the Tomsk Polytechnic University. Geo Assets Engineering, 2017, vol. 328, no. 12, pp. 36-46. In Rus.

23. Adam A.M. Ekologiya Severnogo promyshlennogo uzla g. Tomska. Problemy $i$ resheniya [Ecology of the Northern industrial hub of Tomsk. Problems and solutions]. Tomsk, TSU Publ. House, 1994. $260 \mathrm{p}$.

24. Rikhvanov L.P., Yazikov E.G., Sukhikh Yu.I., Baranovskaya N.V., Volkov V.T., Volkova N.N., Arkhangelsky V.V., Arkhangelskaya T.A., Denisova O.A., Shatilov A.Yu., Yankovich E.P. Ekologo-geokhimicheskie osobennosti prirodnykh sred Tomskogo rayona $i$ zabolevaemost [Ecological and geochemical features of the natural environment of the Tomsk region and the incidence]. Tomsk, Kursiv Publ., 2006. 216 p.

Received: 17 June 2020.

\section{Information about the authors}

Natalya V. Baranovskaya, Dr. Sc., professor, National Research Tomsk Polytechnic University.

Anna Yu. Baranovskaya, postgraduate student, National Research Tomsk Polytechnic University.

Olga A. Kapitonova, Cand. Sc., associate professor, Tobolsk Complex Scirntific Station of Ural Branch of Russian Academy of Sciences. 